\title{
Fostering horizontal knowledge co-production with Indigenous people by leveraging researchers' transdisciplinary intentions
}

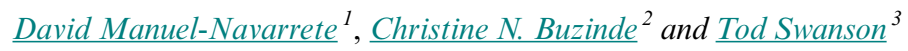

\begin{abstract}
Transdisciplinarity involves knowledge co-production with non-academics. This co-production can be horizontal when equal consideration is given to the contributions from different knowledges and ways of knowing. However, asymmetric power relations and colonial patterns of behavior, which are deeply rooted in academic culture, may hinder horizontality. Using Icek Ajzen's Theory of Planned Behavior, we elicited and analyzed the attitudes, perceptions, and behavioral intentions towards knowledge co-production of a team of seven Ecuadorian biologists while they were conducting fieldwork in Indigenous communities. All biologists acknowledged the benefits of collaborating with indigenous people. However, researchers with less fieldwork experience held unfavorable attitudes towards knowledge co-production. While all criticized the colonial biases of Ecuadorian society, more experienced participants were the only ones who perceived colonial dynamics as intrinsic to dominant scientific practices, and who expressed favorable attitudes towards horizontal co-production. They also perceived lower social pressure against co-production and greater behavioral control (i. e., greater confidence in their ability to perform co-production) than their peers; all of which confirmed their stronger behavioral intention to perform transdisciplinary co-production. Our analysis identified three structural factors affecting researchers' intentions: (1) disciplinarity predispositions acquired through formal education, (2) lack of decolonial approaches in academic curricula, and (3) pressures in academia to do more in less time. Personal decisions by more experienced participants, such as voluntarily engaging with transdisciplinary training or cultivating personal connections with Indigenous culture, appeared to be key enablers of horizontal forms of co-production. Understanding researchers' behavioral intentions might be key to seize, or waste, the decolonization opportunities brought about by the rapid advance of transdisciplinarity that is taking place in fields like sustainability or conservation science.
\end{abstract}

Key Words: co-production of knowledge; Indigenous knowledge; transdisciplinary; horizontal co-production; decolonization

Anthropology had no urgency other than losing precious information about disappearing cultures. They could shed tears [...], but their duty was to record these cultures, then dry their tears with a sight of nostalgia. Now things are more tense [...], it is our turn to be threatened, our turn to realize we will disappear (Latour 2016:339).

\section{INTRODUCTION}

Transdisciplinarity has been described as a new way of thinking about knowledge and inquiry with significant implications on how we design and implement tangible solutions to real-world problems (Bernstein 2015). Researchers who engage in transdisciplinarity usually have the goal of democratizing knowledge production by involving participants from outside academia in the design, implementation, dissemination, and/or use of research. In general, transdisciplinarity seeks to co-produce knowledge through more inclusive dialogues with non-academic actors and their forms of expertise (Darbellay et al. 2008, Beech et al. 2010). Co-production is often justified instrumentally by arguing that it can yield more socially relevant knowledge with increased capacity to leverage societal change (Schneider and Buser 2018, Schäfer and Bergmann 2020). However, coproduction can also enhance research methodologically, epistemologically, ontologically, or axiologically; that is by expanding how knowledge is produced, what counts as valid knowledge, what is knowable, and what it is worth knowing (López-Huertas 2013, Latulippe and Klenk 2020). For instance, transdisciplinary knowledge can be instrumental in supporting and grounding sustainable resource management, but it can also support sustainability research that transcends the conventional dichotomy between objective and subjective viewpoints, or scholarship that addresses complex phenomena as occurring across non-equivalent levels of reality (Nicolescu 2010, ManuelNavarrete 2015).

Despite the growing appeal of transdisciplinary co-production, its implementation is plagued with barriers derived from colonialism, power asymmetries, and centuries of Western/ Northern techno-scientific knowledge supremacy towards nonEuropean cultures. In fact, transdisciplinarity may act as a subtler reproducer of existing power inequalities by inadvertently replicating colonial scripts (Schmidt and Neuburger 2017). Power relations are embedded in current academic institutions and social structures (Fritz and Meinherz 2020), but they are also internalized by researchers through practices, perceptions, and attitudes that may result in low behavioral intentions towards coproduction (Hargreaves 2011). This can continue justifying both exogenously created research designs that omit endogenously generated approaches, and externally conceived solutions to local problems. Furthermore, while researchers who partner with Indigenous communities might be motivated to adopt transdisciplinary perspectives that overcome traditional definitions of Western scientific knowledge, institutional incentives often point to the opposite direction. For instance, Newig et al. (2019) found that including non-academics and their knowledge in research has a negative impact on academic outputs

${ }^{1}$ School of Sustainability, Arizona State University, Tempe, AZ, ${ }^{2}$ School of Community Resources and Development, Arizona State University,

${ }^{3}$ School of Historical, Philosophical and Religious Studies, Arizona State University 
and citations, and doctoral researchers who are involved in transdisciplinary projects are less likely to complete their PhDs successfully.

Coloniality, a structure of management based on attaining control through homogenization, is especially pervasive when coproduction is attempted at the boundary of Indigenous and Western scientific cultures (Mignolo 2017). Indigenous communities' interactions with research are particularly linked to histories of colonialism and complex neocolonial information networks that categorize and archive Indigenous knowledges through methods and categories of Western science (Nakata 2002). Linda Tuhiwai Smith (1999) examined the imperialistic and colonial mechanisms often employed by researchers working with Indigenous communities. Research groups often repurpose colonial constructs that relegate Indigenous groups to culturally submissive roles, ascribe them demeaning monikers, and subjugate Indigenous worldviews (Chilisa 2017). A call to action from Indigenous studies scholars has imbued scholarship on decolonization of research (wa Thiong'o 1986, Tuhiwai-Smith 1999, Simpson 2001, Talbot 2002, Hodge 2012). This body of literature draws on critical analyses on power and inequity; it politicizes knowledge production and co-production; highlights the need for critical consciousness; and problematizes pervasive forms of colonial thinking in theoretical and methodological approaches to research. As a framework, decolonization is both a critique of the past and a conscription for the future; and to this latter point, it highlights the vital role academia should take on countering Euro-centric hegemony.

Sustainability and biodiversity conservation scholars can help to decolonize and indigenize transdisciplinary research by critically and reflexively embracing horizontal forms of co-production with Indigenous cultures. For instance, scholars can embrace pluralistic and non-extractive practices based on fairly recognizing and rewarding Indigenous contributions. In perfectly horizontal co-production, Indigenous People would participate in research on equal footing (Buzinde et al. 2020). Elinor Ostrom pioneered the analysis of co-production in public service provision (Ostrom et al. 1978), paving the way for subsequent explorations of knowledge co-production between scientists and Indigenous communities in relation to sustainable comanagement of resources (e.g., Kofinas 2002, Armitage et al. 2011). There is abundant evidence of the benefits of working with Indigenous People and their knowledges for co-managing natural resources, understanding social-ecological change, and addressing other sustainability challenges (e.g., Bohensky and Maru 2011, Johnson et al. 2016, Athayde et al. 2017, Hill et al. 2020). A recent literature review on the role of Indigenous and local knowledge in sustainability transformations indicates that co-production can substantially contribute to not only better descriptions, but also more plural understandings of transformations (Lam et al. 2020). However, there are fewer analyses of how horizontal forms of knowledge co-production with Indigenous and local people demand significant changes from researchers and science itself. Miller et al. (2020) have recently argued that sustainability science tends to frame coproduction as a normative aspiration, and in doing so it deemphasizes existing power asymmetries. We argue that sustainability science needs to emphasize and address not only power but also coloniality. This means that sustainability researchers need to "make room" and "move over" in Latulippe and Klenk's (2020: 9-10) sense:

To make room is to value Indigenous ways of knowing,
being, and doing on their own terms and to create
culturally-relevant, appropriate spaces for Indigenous
scientific research to flourish within existing knowledge
production infrastructure. [...] to move over is to make
way for Indigenous research leadership on Indigenous
lands. It is to de-center Western science and institutions
as primary sites of knowledge production and leadership
- to give up power and privilege.

Part of the colonial bias the academy has to address is related to the fact that many pedagogical contexts, whether in higher education or earlier, are utterly disciplinary and disallow for the incorporation of Indigenous knowledge (Nicolescu 2010), which is often defined as local, context-specific, adaptive, collective and situated in people's lives (Mistry and Berardi 2016). Raffles (2002) reminds us that Indigenous knowledge is only local in relation to the construct of supra-local science. Viewing dominant and mainstream ways of knowing as the only legitimate knowledge, or as delocalized, is inherently colonial (wa Thiong'o 1986, Talbot 2002). Decolonizing knowledge co-production will require conscientization (Freire 1970); that is, unlearning and facilitation of critical consciousness to make room for awareness of Indigenous epistemologies and politicize what counts as knowledge (Turnhout et al. 2020). Indigenous studies scholars and decolonial theorists have long argued that inter-cultural interactions require the "[c]rossing [of] borders from the academic to the real lives of people" and are often "fraught with tensions and misunderstandings" (Brayboy and Deyhle 2000, 163). According to this conception, researchers have to unlearn what they know and have been taught about research, particularly as relates to work undertaken in Indigenous communities. However, unlearning is rarely considered by transdisciplinary methodologies emerging more generally within science to deal with complexity, sustainability challenges, and, the sustainable management of resources.

This paper explores perceptions and attitudes of academic investigators to understand their behavioral intentions towards engaging in transdisciplinary co-production of knowledge. Our analysis also maps perceptions and attitudes towards coproduction in relation to horizontality. Intentions to perform behaviors account for considerable variance in actual behavior (Ajzen 1991). We empirically examined a group of biologists conducting fieldwork with Indigenous People in a remote community of the Ecuadorian Amazon. Understanding researchers' intentions towards horizontal co-production, vis-àvis the structural barriers existing in academia and society, can inform strategies to advance decolonizing dialogues between majority and minority cultures, and help to overcome pervasive power differentials between academic researchers and the holders of other forms of knowledge, such as Indigenous People. More specifically, this understanding can foster self-reflection, by researchers, on the genesis of their own intentions towards coproduction as well as collective deliberations on how current institutional arrangements in education and academia frame and influence these intentions. Based on our findings, we discuss ways in which transdisciplinary co-production can take into account 
how and why researchers' intentions are embedded in wider sociopolitical contexts and science-society relations, which are often marked by uneven power and coloniality.

\section{ADDRESSING POWER AND COLONIALITY IN TRANSDISCIPLINARITY}

Diverse transdisciplinary approaches and methodologies address knowledge co-production, horizontality, and decolonization in different ways and degrees. Horizontal co-production can happen inter-disciplinarily (i.e., different disciplines participate on equal footing), or trans-disciplinarily (i.e., knowledges from academic and non-academic actors are considered equally valid and their quality is assessed in relation to their own cultural values and worldviews). Addressing power relations is key for horizontal coproduction, but power is hardly central to transdisciplinary discourse and approaches, which tend to focus on the goal of producing socially robust knowledge to address wicked problems.

One of the most popular typologies of transdisciplinarity research, McGregor's (2015) binary classification between "Nicolescuian" and "Zurich" approaches, illustrates that horizontality and power are often marginal in transdisciplinarity. The "Nicolescuian approach" focuses on distinguishing multiple levels of reality and acknowledging that we need a different type of knowledge for each level (Nicolescu 2010). This approach enables horizontality by recognizing the inter-dependent coexistence of unlimited competing cultural truth claims about reality, but it is not clear how this welcomed plurality can solely foster offsetting the hegemony of the Euro-centric science model (Adams 2018). The "Zurich approach" (or mode-2 knowledge production) focuses on solving problems rather than addressing power asymmetries in knowledge production. It assumes that solutions no longer emanate from science, and advocates research partnerships between academics and non-academics (Nowotny et al. 2003). Both approaches seek to end the monopoly of science, but they do not directly challenge the enduring power asymmetries between different ways of knowing.

A broader classification of transdisciplinarity discourses proposed by Klein (2014) is more explicit about power, horizontality and decoloniality. Similar to McGregor's (2015) dual classification, Klein (2014) identified "transcendence" and "problem solving" discourses, but she also identified a "transgression" discourse. This third discourse draws from humanities, critical approaches, and cultural studies frameworks that explicitly aim at ending the privileging of dominant forms of knowledge to foster democratic participation in knowledge coproduction. Similarly, Bernstein's (2015) historical review of the transdisciplinary field also concurs with McGregor's binary classification. However, in line with both Klein's transgressive discourse and the idea of horizontality, he concluded with a call to "think laterally" in order to intentionally bring non-academic participants on an equal footing with investigators (Bernstein 2015:10).

As a form of research that entails co-production, transdisciplinarity is a relational and social process shaped by the power dynamics of the contexts in which research collaborations take place as well as the actors' relative positions within these contexts (Fritz and Meinherz 2020). Addressing power in researcher-practitioner interactions has been recognized in transdisciplinary theory and discourse, but the actual participation of non-academic actors in the research process is often vague and uneven (Brandt et al. 2013, Schmidt and Neuburger 2017). The contrast between the theory and the practice of transdisciplinarity is described by Callard and Fitzgerald (2015) as the "official fantasy of "mutuality". One thing is to acknowledge the necessity of sharing power over the research processes, but another thing is to make power relations a central element around which the research process itself is designed (Bieluch et al. 2016). However, Callard and Fitzgerald (2015: 98) also warn us about falling for another fantasy in which we see relations of power as something that can be "overcome through dialogue, mutual respect, frank talking, and manifestations of emotions appropriate to the situation". Instead, they propose that knowledge co-production will always involve some "adjusting to, precariously acquiescing to, and, on occasion, becoming curiously attached to, states of subjugation" (Callard and Fitzgerald 2015: 99).

Transdisciplinary co-production is currently entangled with asymmetries, coloniality, and other legacies of the hegemonic Euro-centric science model. In this context, academics hold disproportionate power to define, organize, produce, theorize, represent, and control knowledge. Therefore, co-production can easily fall into co-option under the guise of knowledge "integration", "incorporation", or attempts to reach "consensus" among different ways of knowing across cultures (Klenk and Meehan 2015, Schmidt and Neuburger 2017, Lam et al. 2020). This underscores the importance of acknowledging and explicitly tackling power asymmetries and colonial legacies in transdisciplinarity research with Indigenous Peoples. In practice, this means raising field researchers' awareness of structural, discursive, and behavioral barriers to horizontal co-production, including their acquired attitudes and perceptions towards nonacademic forms of knowledge. Ultimately, both researchers and academic institutions need to foster "collective intentionality" towards horizontal co-production and decolonization (ManuelNavarrete et al. 2019).

\section{HORIZONTAL CO-PRODUCTION WITH INDIGENOUS PEOPLE}

When transdisciplinary co-production involves Indigenous cultures, achieving horizontality generally requires overcoming deeply held, and often unacknowledged, perceptions and attitudes (Velasquez Runk 2014). As discussed by Lotz-Sisitka (2017), the very designation of "indigenous" and "nonindigenous" is a Western construct supported through objectification and the colonial logics of "othering", which tends to invisibilize Indigenous ways of knowing that cannot be "fitted" into modern knowledge systems. In particular, phenomenological, cultural, embodied, spiritual, and social-historical connections to the land are devalued by ontological, epistemological, axiological, and other types of assumptions shared by modern science and coloniality (López-Huertas 2013, Lotz-Sisitka 2017). Indigenous knowledge is generally framed as local, context-specific, adaptive, collective, and situated in people's lives. However, the belief that scientific research is somehow separable from the local cultural contexts where it is produced can promote extractive behaviors that relegate Indigenous ways of knowing to accessory roles.

The horizontal approach discussed here seeks balancing power disparities between Indigenous worldviews, perspectives, needs and questions, and Western canons of knowledge production and 
problem-solving (Adams 2018, Apgar et al. 2009). A key challenge is avoiding the temptation of codifying contextual knowledge into any "universal" language of transdisciplinary science. Instead, Santos (2014) suggests that curiosity and openness to otherness must guide iterative dialogues between Indigenous and nonIndigenous knowers, and Buzinde et al. (2020) consider the key role of boundary individuals and knowledge brokers in facilitating collaborations across cultural boundaries that respect difference. Horizontality highlights that science is, in fact, just one culturally specific knowledge production system amongst 6,900 documented culturally and linguistically-mediated Indigenous knowledge systems (Cole 2017). Research that is practically relevant and socially inclusive needs to start recognizing science's cultural biases. Such as, for instance, the historical fact that science has been culturally white, Euro-centric, and patriarchal (Grosfoguel 2011, Mamdani 2019).

Horizontal co-production requires that Indigenous voices participate in the definition of transdisciplinarity as a transcultural field of research (Nicolescu 2014, Frandy 2018). For example, Cole (2017) characterized his own Indigenous (Mâori) transdisciplinarity in terms of a value-based approach to knowledge development created over centuries of maintaining the survival and wellbeing of whânau Mâori (translated by Cole as the "Mâori family ecosystem"). This Mâori transdisciplinarity emerges from " animistic' identification with the 'natural world" as a genealogical extension of the human Mâori family. By contrast, [...]'western culture' came to transdisciplinary methodology and practice as a result of attempts to extend [...] classical western scientific method." (Cole 2017: 137). Cole concludes that (horizontal) dialogue between Indigenous and Western "transdisciplinarities" is particularly pertinent in New Zealand given Western science's failure to maintain the survival and wellbeing of whânau Mâori.

Horizontal transdisciplinarity challenges power asymmetries inherent to Western researchers' socially-attributed roles, and their institutional positions as producers of knowledge, as well as related financial and social privileges. In addition to these organizational asymmetries, there are epistemic and value-laden conflicts, unresolvable or very difficult to solve, between Western and Indigenous knowledge systems (Koskinen and Mäki 2016). Decolonial approaches are useful in identifying, making visible, and articulating these asymmetries as well as finding "interstitial spaces" between opposing epistemologies and values (Cram and Phillips 2012). In addition, researchers working in the field with non-academic actors can question, in-situ, and sharpen their awareness of their own and others' perceptions and attitudes towards co-production.

This paper contributes to knowledge of how field researchers' perceptions and attitudes affect their behavior and positionality in the co-production process, as well as what ideas, interests, claims, and scopes of action they bring to their relations with other participants (Rosendahl et al. 2015). Researchers may unwittingly infuse co-production practices with dominant norms, rules, and discourses about, for instance, who controls resources or what needs to be researched and how (Zingerli 2010). We apply the Theory of Planned Behavior (TPB) as an analytical lens to explain co-production behavior as a function of "individuals' attitudes" (is the behavior perceived positively or negatively?), "social norms" (which social pressures are perceived?), and "perceived behavioral control" (how easy is the behavior's performance perceived by the individual?) (Ajzen 1991, Grilli and Notaro 2019). TPB proposes that these are the three main determinants of any behavioral intention (is the individual ready to perform the intended behavior?). Applying TPB to the analysis of our interview data allows us to identify patterns of behavioral intentions towards different forms of co-production in collaborations with Indigenous Peoples.

\section{METHODS}

\section{Study area}

The Napo and Curaray rivers, where most Waorani reside and where Gomatan and Geyedape are located (Fig. 1), is a biodiversity hotspot hard to access by biologists and other researchers (Beckerman et al. 2009). The first documented contact occurred in 1956 when five North American male Protestant missionaries landed their plane on a sandy beach by the Curaray River with the goal of converting the Indigenous Peoples of the region to Christianity. All five missionaries were killed, reportedly over a cultural misunderstanding. News reports about the incident widely permeated US mainstream media; "publicity surrounding the missionaries' deaths both sensationalized [the Waorani] and dehumanized them" (Long 2019, 23). Some accounts attribute the incident to the "long history of outside aggression against the Waorani" which may have "fueled their anger" towards the missionaries (Long 2019, 19). The incident also illustrated the vehemence of Western religious institutions in imposing their value system and altering Indigenous ways of being and knowing. Peaceful contact with the Waorani was made two years after the tragedy by two missionaries, (spouses of the killed men) Rachel Saint and Elizabeth Elliot, who created a settlement that with time housed many Waorani (Beckerman et al. 2009). It should be noted that, to date, there are still groups of uncontacted Waorani Peoples who are voluntarily isolated and reside deep within the Amazon forest.

There are many recent cases of inter-cultural conflict between Indigenous communities and groups of Spanish descendants called Colonos. Encroachment on Indigenous Peoples' lands by Colonos is increasingly a major source of conflict in Ecuador. The Waorani inhabit an expansive and biodiversity-rich area under high pressures from logging, oil exploration, and illegal trading of exotic species. Cognizant of geographical, infrastructural, and economic limitations, some Waorani people are hopeful that tourists and field researchers will generate needed revenue while offering opportunities for capacity building, and forms of participation in the global economy that do not involve losing their culture (personal communications with our Waorani partners). But for these hopes to materialize field researchers need to have a disposition towards co-production of knowledge.

Access to the two Waorani communities, where interviews were conducted, requires five hours in dugout canoes and several hours of driving on dirt roads. Travel time is contingent upon water levels and can double in the dry season. There are basic clinics but no hospitals in the area (emergency cases are airlifted out in a three-passenger plane) and this absence might have indirectly contributed to sustaining the local culture of ethnobotany. The Waorani worldview entails a view of the physical and social world as undivided (Rival 1993). 
Fig. 1. Location of the Andes and Amazon Field School main station (Iyarina), and the two Waorani communities where interviews were conducted (Gomatan and Geyepade). Basemap source: Landsat / Copernicus, accessed through Google Earth

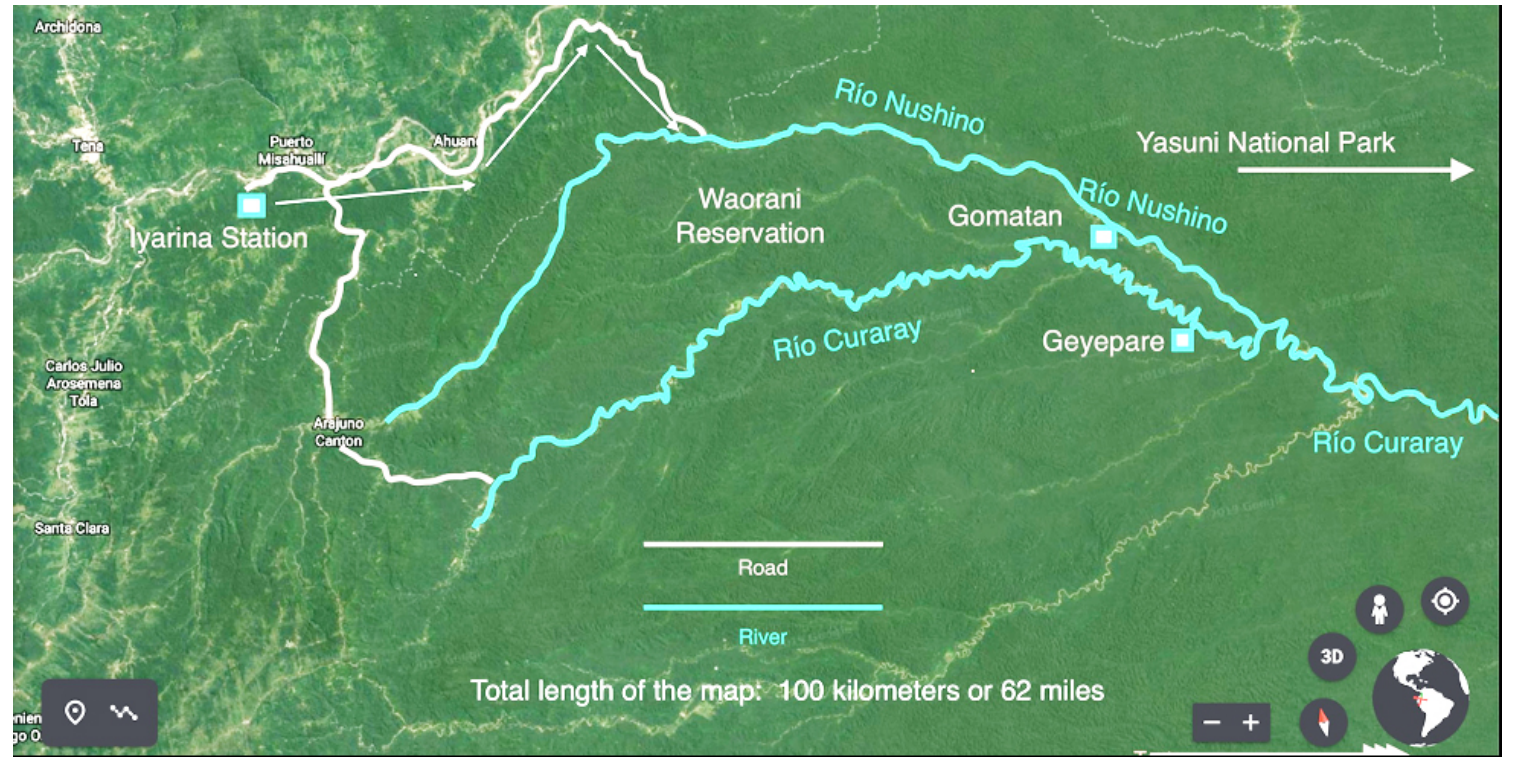

\section{Data collection}

We interviewed a team of fieldwork-engaging biologists while we were implementing a transdisciplinary project in Ecuador. The transdisciplinary project intended to advance sustainability in Indigenous communities through expanding the operations of the Andes and Amazon Field School (AAFS) into two remote Waorani communities, Gomatan and Geyepade (Fig. 1), composed of two extended Waorani families (around 30 members each). The AAFS was founded by an Ecuadorian-Kichwa family in 1999 and employs mostly Kichwa people to foster collaborations while teaching Indigenous languages and biocultures to Western researchers and students. The AAFS is based at Iyarina, a station by a Kichwa community near Tena (Fig. 1), where it provides educational and research tourism infrastructure and inter-cultural co-production processes by acting as a boundary organization that connects academics and Indigenous partners (Buzinde et al. 2020).

The team of field biologists interviewed for this study gained access to Waorani communities through the AAFS networks. The authors travelled together with the team of biologists in 2018 and stayed together for about ten days. The biologists' main goal was to assess water quality, and the populations of birds, bats, insects, amphibians, snakes, and fish. We observed and interviewed the team of biologists while also working with Waorani people in creating infrastructure to host students from study abroad programs. Biological fieldwork started with community meetings organized by the biologists to explain the research and coordinate collaboration. Almost all community members participated in supporting the biology research, and they, as well as the community as a collective, were remunerated according to amounts previously negotiated with community leaders.

Interviews were the selected method for this study because they allow participants to describe meanings they associate with certain aspects and experiences of their life worlds (Kvale 1996). The interviews were semi-structured and took place during various times of the day, before or after the biologists had gone out in the field, accompanied by members of the local community, to collect biological samples. Topics covered in the interviews included the researchers' approach to Indigenous knowledge, involvement of community members in scientific research and influence of broader societal views about Indigenous Peoples. The same open-ended questions were asked of all participants. All interviews were taped upon obtaining consent from the participants; each interview ranged from 30-40 minutes. The research questions and transcripts were translated from English to Spanish and back translated; the authors are fluent in English and Spanish whilst the participants were Spanish speakers. We did not interview Waorani people because our focus was on the researchers' behavioral intentions. We also wanted to protect our long-term partnership with these communities by avoiding an informant-researcher relation.

Interviews were conducted with the group of 7 biologists ( 5 women and 2 men, 4 in their 20s and 3 in their 40s); gender and age specificity is not provided in the findings to preserve anonymity. However, we make reference to older and younger researchers to discuss general patterns in the data. One of the older participants self-identified as having an Indigenous background, rooted in the Ecuadorian highlands. The majority of participants had years of fieldwork experience in local communities, but some of the younger participants had very limited fieldwork experience. They were all Ecuadorians, some foreign educated but they all worked in partnership with a local prestigious university through which funding for their biological research had been secured. None of the participants had previously been to the Waorani communities wherein the interviews were conducted. Research approval was granted by our 
university Institutional Review Board, which is responsible for ensuring minimum risk to research participants.

\section{Data analysis}

An iterative analytical process was adopted in this study, which allowed for a repetitive and thorough evaluation of participants' accounts and intertextual links as well as the connections between the data and theory. As themes and sub-themes were identified and clustered across participants, diverse patterns of researchers' perceptions and attitudes towards co-production emerged from the iterative process. We are cognizant that our small sample limits any pretension of generalizability, but it provides highly contextualized insights that capture a diverse set of perspectives, including both positive and negative attitudes towards transdisciplinary knowledge co-production and towards different forms of horizontality. The identification of preliminary categories was documented during interviews and through the iterative and inductive process stable themes, related to the questions posed, were developed. Codes were identified by analyzing the transcribed data line-by-line and then combined into consolidated major themes and nested subthemes (Weston et al. 2001).

Themes and subthemes were interpreted and classified along the variables of Ajzen's (1991, 2002) Theory of Planned Behavior (TPB), which explains individuals' intentions to perform certain behaviors as the result of three determinants (Fig. 2): (1) Attitudes toward the behavior: the degree to which researchers viewed coproduction favorably or not; (2) Subjective norms: the perceived social pressure to engage, or not, in co-production; and (3) Perceived behavioral control: the perceived ease or difficulty, according to past experience and anticipated obstacles, of performing co-production (self-efficacy) plus the extent to which performance is up to the actor (controllability).

Fig. 2. Determinants of behavior and their relations according to the Theory of Planned Behavior (Ajzen 1991)

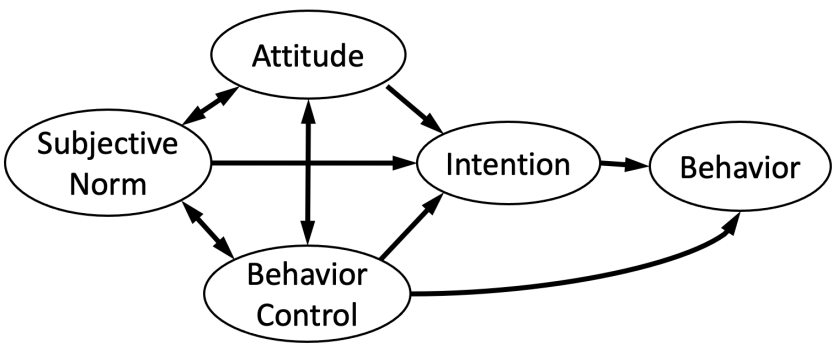

\section{RESULTS}

Attitudes toward knowledge co-production and horizontality

All participants recognized or ascribed some value to Indigenous and local knowledge systems, which the Intergovernmental Platform on Biodiversity and Ecosystem Services (IPBES) defines as "a cumulative body of knowledge, practice and belief, evolving by adaptive processes and handed down through generations by cultural transmission, about the relationship of living beings (including humans) with one another and with their environment" (Diaz et al. 2015:13). Researchers agreed that involving locals as collaborators (or participants) in scientific research has practical benefits. For instance, all perceived that locals are already more capable at carrying out certain research tasks, such as locating species, and that with some training they can also surpass academics in other tasks such as placing sensors or collecting certain data. One interviewee even associated collaboration with his/her own maturation as a researcher due to the opportunities it offered for intercultural exchange and self-reflection. Overall, there was consensus about collaboration with Indigenous Peoples being beneficial to accomplish certain tasks, accelerating them, and facilitating fieldwork. However, attitudes towards more horizontal forms of knowledge co-production were strikingly diverse with some highly experienced field researchers perceiving them positively, while younger and less experienced field researchers negatively or neutrally.

Some highly experienced researchers displayed favorable attitudes towards codesigning research (e.g., community mapping to inform sample collection site), but not to the point of contemplating co-analyzing results, and co-authorship. They also pointed to the advantages of adapting research protocols and including Indigenous knowledge in their design:

\section{You either create a protocol a priori or you adapt it and create something tailored to the communities you plan on working with. [...] I always include local scientists to combine local and other knowledges.}

In general, highly experienced researchers agreed that research in Indigenous settings benefits from three types of adaptations, which are indicative of positive attitudes towards co-production. First, adapting to locals' particular sense of time. In particular, deaccelerating while avoiding strict timelines. Second, willingness to participate in local rituals and practices, when invited. Third, maintaining an attitude of respect, sharing, openness, and flexibility. Overall, adaptability was perceived as hinging on the researchers' willingness to leave personal needs aside and to stay outside one's comfort zone. However, only some highly experienced researchers expressed positive attitudes towards horizontal forms of co-production. They valued Indigenous knowledges vis-à-vis scientific knowledge and recognized some equivalent epistemological standing between the two. For instance: "often they know more than us"; "what is referred to as their local scientific knowledge"; or "their sense of being and knowing". Although not entirely explicit, these excerpts indicate some openness to genuinely believe that scientific research is commensurate with Indigenous ways of knowing.

The instrumental value of Indigenous knowledge was consensually acknowledged, particularly in terms of carrying out scientific work more effectively (e.g., "they [locals] tend to know where to locate certain species"). Culturally, it was generally perceived that Indigenous knowledge is more attuned to the "the reality of the Indigenous community" and therefore valuable for these communities in ways that science cannot deliver. However, while attributing cultural value to Indigenous knowledge can be seen as a positive attitude towards co-production, it is also an expression of Western culture's habitual separation between science and culture (Nicolescu 2014). Disagreement was most evident in terms of attributing intrinsic value to Indigenous knowledge. The majority of participants were unfavorable to the idea of epistemological parity between Indigenous knowledge 
and science, thus displaying negative attitudes towards horizontal co-production.

Highly experienced researchers who also showed favorable attitudes towards horizontality still tended to use terms like "integrate", "combine", or "link", which do not bring power relations or asymmetries to the fore (Turnhout et al. 2020). The most explicit references to horizontality were in terms of making scientific forms of knowing permeable to other forms of knowing; for instance, ideas such as, "we have to change certain protocols" or "enrich each other's sense of knowing". Overall, they acknowledged a certain degree of equivalence, correspondence, and unique contributions from Indigenous knowledge. The following excerpts are exemplary of these sentiments: "treat them as equal to educated scientists", or "[1] earn and be educated by the community". However, it is important to note that no participants explicitly addressed scientific knowledge as culturally-specific. Horizontality was generally implied in terms of "elevating" certain aspects of Indigenous knowledges to the status of science by situating them beyond their cultural specificity and somehow on par with science. The following quote is illustrative of this view: "[a]cquire knowledge at the cultural level given that we are in an Indigenous community but also figure out ways to link this knowledge to scientific thinking".

Other highly experienced field researchers showed favorable attitudes towards co-production, but in a very limited sense and leaving no room for horizontality. They generally highlighted the culture-science divide by making clear distinctions between, on the one hand, valid knowledge, and, on the other hand, beliefs (e.g., "someone has to be in charge of unifying their cosmovision with scientific information because science is so abstract and it may never be compatible with what they do on a daily basis"). They tended to see the process of co-production in asymmetric or vertical fashions, as is indicated in the following quote: "[locals] learn a number of methodologies and more information... and we also get lots of information... they help us locate research sites". These participants valued local involvement in research but only to the extent that it served their research goals. They also expressed unfavorable attitudes towards knowledge co-production. For instance, in one participant's account, involvement of locals in research aids only in the acceleration of data collection:

The community has a lot of knowledge and this is great
because scientists need to save time and optimize all [...]
locals are the best people to help you take advantage of
the location. So, I would not say that this has changed my
work but involving them has helped me accelerate and
facilitate my work.

Similarly, another participant commented that:

...locals can be involved only because they tend to know where to locate certain species in a way that researchers from the outside may not. So as guides they are excellent, and this should be the extent of their involvement in research. For instance, if you are doing research on mushrooms they will know where to locate them or on certain other plants. So simply as guides and nothing else.

Unfavorable attitudes towards any form of knowledge coproduction were uttered particularly amongst the least experienced field researchers. Scientific knowledge was perceived as either superior or the only legitimate form of knowledge. For some participants, incorporating knowledge or insights from Indigenous Peoples was perceived as polluting or biasing science. These informants regarded collaboration with local people as transactional and purely instrumental. Even ethnobiology research was considered with suspicion as it can contaminate scientific results; diminishing the rigor required of scientific research. This shows that being aware of transdisciplinary alternatives does not automatically engender favorable attitudes towards co-production.

All participants showed more favorable attitudes towards coproducing solutions than co-producing knowledge. There was consensus that Indigenous People "need" to be involved in nature conservation and in implementation of solutions to local problems. The most enthusiastic participants expressed that coproduced solutions should include consideration of Indigenous knowledge in the design of solutions; co-generation of technologies; collaborative teams; and participation in the application of scientific results. More generally, involvement was associated with improving outcomes and the effectiveness of solutions because as stated by one of the interviewees: "at the end of the day locals are the ones who remain in the area".

When asked whether knowledge co-production benefits Indigenous collaborators, all groups considered both pros and cons. The most commonly mentioned benefit, as perceived by researchers, was money and access to knowledge. All informants stressed the importance of financial compensation for local collaborators. Another common concern was that collaborating takes time away from daily subsistence practices. Cultural impacts resulting from exposure to Western culture or appropriation of Indigenous knowledge were also mentioned by some as potential threats. The establishment of personal relationships and facilitation of consensus-building processes were mentioned as vital to avoid misunderstandings.

Finally, locals were perceived by all informants as potential users of scientific knowledge. Less experienced field researchers emphasized skills and specific data that locals may acquire or use from scientists. More experienced field researchers focused on the challenges of communicating and translating scientific findings in ways that locals are able to understand and use. Effective communication was described in terms of understanding locals' points of view and their discursive mannerisms; avoiding jargon; residing within and being part of the community; and developing trust.

\section{Subjective norms}

In TPB, subjective norm refers to the perceived social pressure to perform, or not to perform, a behavior. In his evaluation of available empirical evidence confirming TPB's predictive capacity, Ajzen (1991) found that attitudes and behavioral control tended to overshadow the influence of subjective norms on intentions for a set of analyzed behaviors. In our case, all participants perceived the larger social context in Ecuador as promoting marginalization, discrimination, and racism; thus, potentially hindering collaboration with local people. This suggests a general perceived social pressure to not engage in coproduction, but further research would be necessary to evaluate the actual influence of these perceived pressures on the researchers' behavioral intentions. 
When asked about how the social context influences mainstream perceptions of Indigenous communities in the nation, interviewees depicted prevalent inequalities and preponderance of stereotypical frames. Colonial biases and practices in Ecuadorian society were criticized by all participants, but only those researchers with favorable attitudes towards horizontal coproduction implied that the normal practice of science has a builtin colonial bias. The rest were aware that social colonial biases may influence the practice of science but did not perceive colonial dynamics as intrinsic to science. Some of them depicted science as completely apart from society's colonial predispositions. They justified this separation disciplinarily by regarding community and community related issues as 'social' issues which from their vantage point were not directly related to the natural sciences. Reflecting on the social dimensions, one participant asserted that full consideration of these matters reduces the legitimacy of science:

Ialways felt that the social component was vital to include in research projects. But incorporating the social can also lead to biases or biased results that a real biologist would not have to deal with. We focus on capacity building but science is science and there is no changing that because it has to be rigorous to be valuable and done right.

The above vantage point is thus indicative of the fact that the participant has not reflected on the vital role Indigenous knowledge plays in understanding the natural and cultural worlds.

Interestingly, researchers with less favorable attitudes towards coproduction were particularly graphic in their criticism of Ecuadorian society's prejudices. For instance, one participant stated that "[m]any still view Indigenous communities as savages and wild and people who will kill outsiders...[with] no common sense or rationality". Notably, such criticisms of society were absent in their views of science. Some in this group were also remarkably articulate in their discussion of issues related to colonial views, prejudice, hierarchy, and racism. Surprisingly, those most favorable towards horizontal co-production used a milder tone and were more cautious in their criticism of Ecuadorian society. This may suggest that they perceived less social pressure against co-production.

\section{Behavioral control}

Behavioral control is the perceived ease or difficulty of performing a behavior according to past experience and anticipated obstacles. It denotes the subjective degree of control over performance of the behavior itself, not over the outcomes of the behavior (Ajzen 2002). All participants identified difficulties to any form of collaboration with Indigenous communities due to constraints imposed by the Ecuadorian academic system and its increasingly competitive and neoliberal culture. The system was perceived as promoting decontextualized research designs by encouraging short-term, discontinuous, and intensive fieldwork campaigns that disallow opportunities to share results or develop relationships with locals. These obstacles were contextualized in the growing pressures in academia to do more (i.e., produce more research outputs) in less time. There were also references to lack of incentives to collaborate and poor practical training on how to engage with non-scientists. The habitual existence of tensions within communities was also identified as making collaboration more difficult.
Overall, participants agreed that academia and education, writ large, do not promote meaningful involvement of Indigenous Peoples in research. However, contrary to the distribution of perceptions about the Ecuadorian social context presented above, participants with favorable attitudes towards horizontal coproduction clearly surpassed their counterparts in the detail, depth, and eloquence of their criticism, analyses, and opinions about structural difficulties created by the dominant academic culture. They identified indoctrinations, teaching styles, and inadequate curricula as root causes of misperceptions and biases, which ultimately constitute major barriers for collaboration and knowledge co-production.

Participants with less favorable attitudes towards co-production did not perceive the academic and education systems as problematic in themselves, but rather insofar as they indirectly impose logistical constraints, such as growing pressures to produce more in less time. One participant mentioned that the extensive work needed to collect data meant not having time to connect with the community. Underpinning this assertion is the assumption that one only makes time for legitimate and important research-related tasks and according to this analogy, interactions with members of the communities in which research is taking place is peripheral to the goal of research. This particular participant also attributed the role of liaising with the community as central to development projects, but not to research-related activities:
I have been on trips like these 3-4 times a month, some are short and others are long. In my work we have very little contact with the communities given the amount of work we have to do in terms of data collection and it is exhausting and does not allow for contact with communities.

Interestingly, highly experienced participants who also held unfavorable attitudes towards horizontal co-production tended to highlight their status as "scientists", and/or disciplinary affiliation as "biologists," and in so doing perhaps reducing their perception of behavioral control over performing co-production. In the excerpt below one participant asserts his/her title and then proceeds to offer an account of how the inclusion of locals in research is justified as long as it serves the goals of the researcher:

I am a biologist so the only change is to be attentive to things that could compromise the livelihoods of locals. I have locals in mind but not as active participants in my scientific work. I talk with them (locals) to the extent of coming to a consensus regarding what is going to be done, who is going to help us accomplish those goals so as to not have misunderstandings.

\section{Changing attitudes towards horizontal co-production}

Researchers with favorable attitudes towards horizontal coproduction recognized that such attitudes had grown on them after graduation and are indeed not the norm. As described by one participant who attributes this trend to the education system:

It is not common to see biologists adopt the practices I have described because many of us cannot let go of the perception of academia that we have been indoctrinated in. It is difficult for many academics to adopt new approaches and many do not feel comfortable working 
with Indigenous communities. They prefer to work in the manner they were taught in school which tends to not include participatory approaches to research. Here in Ecuador, there is a lot that has been done on this front in part because we are doing some interesting work on ethnobiology; but generally, this is not mainstream perspective.

The excerpts below richly describe how the attitudes of this participant changed over time, including the adoption of practices more attuned with horizontal transdisciplinarity:

I started this work in 2001 and a lot has changed. What you get in class is one thing and when you are in the field there is a difference. I have changed my approach. There are those who have a strict agenda and are inflexible. But here time is seen differently and you have to change because here people stop and drink chicha la fermented beverage]. We have to deaccelerate while here and with a smile because people in these communities are always happy because they are immersed in nature. We have to standardize research but here you have to change certain protocols.

The above excerpt indicates that change entailed accounting for differences in perception of time when working with communities. The participant gives the examples of allowing for engagement in rituals, traditions, and/or practices that are not directly related to scientific research but that are essential to the establishment of a relationship between community members and research teams.

Another participant alluded to the process of increasingly valuing Indigenous knowledges and incorporating them in research protocols:

I started getting data and that was the main objective but with time Irealized that it was not just about getting data, one had to share day-to-day events, be ready to leave your needs aside and cater to them. [...] Someone from outside would not survive this alone, local input and support are needed. You have to interact with them, share knowledge and learn from them. [...] treat them as equal to educated scientists.

However, some participants with less fieldwork experience were less open to shifting unfavorable attitudes towards horizontal forms of exchange. In explaining why his/her research approach had not changed as a result of working in the community, one participant juxtaposed his/her biological approach to certain types of researchers who, from his/her perspective, are less scientific because they tend to incorporate local ways of knowing:

For instance, I am not in agreement with what ethnobiologists do, which is to take information from local Indigenous groups and incorporate it in scientific studies, because that is not science. Sometimes locals talk about curative plants but those could be placebos and to include such elements in research work biases the research and is not scientific. I thus am not in agreement with such approaches, at all.

The overall assumption was that Indigenous knowledge needs to be subjected to validation from science.

\section{DISCUSSION}

Our findings show a diversity of interconnected perceptions, attitudes, and behavioral intentions towards co-production and horizontality. Favorable versus unfavorable attitudes were distinctly connected to participants' perceived ability to perform co-production (behavioral control), and social pressures against co-production (subjective norms). Figure 3 builds on the relationships between the three determinants of TPB to sketch three patterns of behavioral intentions towards co-production as expressed by the researchers who participated in this study: (1) horizontal co-production; (2) vertical co-production; and (3) aversion to co-production. These patterns are consistent with the actual behaviors observed during our fieldwork. The horizontal co-production pattern tended to be articulated by older researchers with high fieldwork experience, while vertical coproduction and aversion to co-production were consistently expressed by less experienced and/or younger participants.

Fig. 3. Identified patterns of researchers' behavioral intentions towards co-production according to TPB Determinants of Behavior. Notes: TPB: Theory of Planned Behavior; +/-: favorable/unfavorable attitude, positive/negative social pressure or high/low behavioral control for co-production


The diversity of attitudes and the split across age groups was unexpected. Our initial assumption was that younger generations would hold more positive attitudes towards carrying out transdisciplinary co-production, as we were assuming that both academia and Ecuadorian society are increasingly veering away from coloniality and academic silos. We were puzzled by some participants' open abidance by colonial scripts to substantiate their views that communities should not be active collaborators 
in the research process. Even though our sample is not representative, this finding suggests deficits in formal education in Ecuador, which does not seem to encourage graduates to value and engage in transdisciplinary and decolonial approaches to research.

Researchers with favorable attitudes towards horizontal forms of co-production expressed softer criticisms of existing colonial biases in Ecuadorian society. This was another unexpected finding. However, from the standpoint of TPB, it might indicate a perception of lower social pressure (subjective norm) against co-production, which would further support the favorable attitudes and behavioral intentions expressed by these researchers. Reasons for such lower perceived pressure might include exposure to transdisciplinary training (e.g., ethnobotany), or personal connections with Indigenous cultures. That is, the fact of belonging to social sub-networks, which are more favorable to coproduction than the average of Ecuadorian society, would make these researchers perceive lesser social pressures against coproduction. In terms of perceived behavioral control, these researchers were much more articulate and poignant in recognizing and describing the structural difficulties posed by academia's institutional culture, including the field of biology as a whole. However, unlike their peers, they did not perceive coproduction as detrimental to their own careers, suggesting higher degrees of perceived control to perform transdisciplinarity

Overall, there was a pattern linking perceptions of lower social pressure, fewer difficulties to perform co-production, and favorable attitudes towards it, particularly in the case of older and highly experienced researchers. These researchers recognized that their perceptions and attitudes had changed over the years as they tried to enhance local engagement in their research. This indicates that accumulated fieldwork experience working in local communities can change the attitudes acquired through formal education. However, other researchers with comparable amounts of fieldwork experience did not change their attitudes. As mentioned above, this variance could be explained by career choices as well as social/ethnic background and personalities. Thus, other subjective factors not captured by the notion of "subjective norms" might explain behavioral intentions toward co-production.

On the opposite side of the spectrum, some researchers with less fieldwork experience expressed a very different pattern of behavioral intentions towards co-production (Fig. 3). First, they did not link science to the larger colonization biases that they identified in Ecuadorian society, thus tending to situate science outside of society. In fact, they were highly suspicious of transdisciplinary knowledge co-production and appeared to have naturalized and internalized disciplinary prejudices that highly experienced researchers identified as obstacles to co-production. Second, they were aware of, albeit unacquainted with, decolonial approaches to research, wherein elements such as cross-cultural proficiency and anti-extractive approaches to research resonate. They could not come up with any reasons that they perceived as legitimate enough to significantly change their methodological approaches. They held true to the paradigm taught in school. For instance, one participant mentioned that the only change s/he could report as resulting from working with local communities was in the choice of sampling areas and, in his/her recollection, "[i]n the scientific part, not at all".
Even though some younger researchers expressed mixed attitudes (favorable and unfavorable) towards vertical co-production, they all were explicit about their low behavioral control (Fig. 3). Thus, while not all younger researchers were ideologically opposed to co-production or considered that altering their methods to include other knowledges was detrimental to research or antiscientific, they all agreed that it would take time away from doing "actual" work, thus reducing productivity and hindering career success. This perception has been confirmed by research on the higher challenges of transdisciplinary researchers to produce academic outcomes in comparison to disciplinary research (Newig et al. 2019). The culture of foregrounding and maximizing measurable outcomes has been discussed in relation to neoliberal discourse and practice in academia (Bell and Pahl 2018). Referring to the notion of expediency in research, some decolonial scholars have used the term "helicopter scientists" to describe individuals that merely rush in to collect data and leave while including locals to the extent that they can expedite the process; this process can indeed lead to ingrained perceptions of mistrust towards scientists by Indigenous community members (Adams et al. 2014).

Overall, our research explored the complex relations between perceptions, attitudes, and intentions of researchers performing co-production behavior. We identified three distinctive patterns of behavioral intentions towards co-production from a small group of field biologists. The diversity of patterns reflected differences in age and fieldwork experience. However, accumulated experience does not guarantee positive attitudes towards horizontal co-production. The patterns depended on biographic trajectories and subjective decisions, but also on university training, research incentives, academic culture, and perceptions of colonial prejudices existing in society. It is important to acknowledge that they reproduce pervasive power differentials between academic researchers and the holders of other forms of knowledge such as Indigenous People. All these factors are tied to power relations within academia and between majority and minority cultures. Our findings suggest that horizontal co-production can be fostered from academic institutions through curricular strategies, adequate research incentives, and changes in academic culture. Individual researchers can also contribute by self-reflecting on their attitudes and perceptions and understanding how their behavioral intentions towards co-production arise from them. A critical change to foster horizontality is greater recognition of the vital role Indigenous knowledge plays in understanding the natural and cultural worlds. This is particularly true when one considers that the cultural identities of Indigenous Peoples are inextricably linked to the natural world.

\section{CONCLUSION}

Extant research indicates that transdisciplinary knowledge coproduction can contribute to the decolonization of scientific research (Buzinde et al. 2020). We examined perceptions, attitudes, and behavioral intentions of a team of Ecuadorian biologists conducting fieldwork in two remote Waorani communities in the Amazon. Participants with less fieldwork experience tended to show unfavorable attitudes, and perceive less capacity and stronger social pressures against co-production. This highlights the importance of research on how to increase awareness of decolonial frameworks and their applicability to the fieldwork context. Of particular interest was the fact that some 
participants with extensive fieldwork experience still expressed doubts about the actual value of Indigenous knowledge beyond practicalities of facilitating the carrying out of scientific research tasks for researchers. We showed how this unfavorable attitude towards horizontal co-production might have been reinforced by perceived pressures and low behavioral control linked to careerism and the highly competitive culture of neoliberal academia. We found a persistent underlying assumption that Western theoretical thought is the only knowledge informing, or that should inform, the scientific realm. Resultantly, a limiting worldview and a lack of awareness of the value of cross-cultural interactions pervades. This is problematic because opportunities to co-produce transdisciplinary knowledge and co-create solutions to global problems, such as those related to ecology, are inevitably lost when limiting worldviews on knowledge production are espoused.

Views of taking into account power relations and colonial legacies when conducting fieldwork in Indigenous communities were not a commonly shared vantage point. In fact, no participants in our study considered scientific knowledge as culturally specific. This suggests that a reflexive process for researchers is needed to allow for critical assessments of their own attitudes and perceptions, and related socio-political histories, as well as, uncovering power relations and coloniality in research practices. This process could then set a foundation on which researchers can begin to contemplate how to unlearn certain attitudes towards Indigenous knowledge systems and transdisciplinarity with the goal of accounting for mutually beneficial research-related outcomes. Understanding this interaction between Indigenous cultures and the techno-scientific culture is crucial to advancing horizontal forms of transdisciplinary knowledge co-production as well as tackling complex sustainability problems through transdisciplinaryoriented solutions. Key systemic barriers embedded within the structures of academia and internalized by researchers in the form of behavioral intentions pose a major roadblock.

A key element that emerged from the data is the role of higher education in the provision of knowledge and skills that enable field researchers, operating in Indigenous or marginalized contexts, to do their job in a manner that meets the goals of the research product but also contributes to horizontal forms of transdisciplinary co-production. To accomplish this, there is a need to inculcate critical consciousness and decolonizing pedagogies as crosscutting curricula across disciplines in higher education, particularly research methods or community service classes. The inclusion of histories of tribal communities in pedagogical contexts requires the facilitation of what Freire (1970) refers to as critical consciousness. This decolonial approach allows for socio-political conversations on cognitive imperialism, histories of colonialism, and omission of non-Western epistemologies (Battiste 1998, Dei 2000). It also allows for conversations about local and Indigenous worldviews, as well as ethical issues related to community-based research.

Responses to this article can be read online at: https://www.ecologyandsociety.org/issues/responses. php/12265

\section{Acknowledgments:}

Funding for this project was granted by the Global Consortium for Sustainability Outcomes to foster synergies between research, educational tourism, and the biocultural sustainability of Indigenous communities. We are grateful to the team of biologists and the members of the Waorani community that made this study possible. We thank the anonymous reviewers for their extremely thorough and comprehensive comments.

\section{Data Availability:}

The data are not publicly available due to containing information that could compromise the privacy of research participants. Research approval was sought and granted for this study by Arizona State University's Institutional Review Board (IRB \# 00008895) as well as permission from the Indigenous leaders of the Waorani communities.

\section{LITERATURE CITED}

Adams, D. 2018. An experience-based perspective on the relationship between Indigenous and Western epistemic systems in research. Evaluation Matters-He Take Tô Te Aromatawai 4:35-66. https://doi.org/10.18296/em.0028

Adams, M. S., J. Carpenter, J. A. Housty, D. Neasloss, P. C. Paquet, C. Service, J. Walkus, and C. T. Darimont. 2014. Toward increased engagement between academic and indigenous community partners in ecological research. Ecology and Society 19(3):5. https://doi.org/10.5751/ES-06569-190305

Ajzen, I. 1991. The theory of planned behavior. Organizational Behavior and Human Decision Processes 50:179-211. https://doi. org/10.1016/0749-5978(91)90020-T

Apgar, J. M., A. Argumedo, and W. Allen. 2009. Building transdisciplinarity for managing complexity: lessons from Indigenous practice. International Journal of Interdisciplinary Social Sciences 4(5):255-270. https://doi.org/10.18848/1833-1882/ CGP/v04i05/52925

Athayde, S., J. Silva-Lugo, M. Schmink, A. Kaiabi, and M. Heckenberger. 2017. Reconnecting art and science for sustainability: learning from indigenous knowledge through participatory action-research in the Amazon. Ecology and Society 22(2):36. https://doi.org/10.5751/ES-09323-220236

Armitage, D., F. Berkes, A. Dale E. Kocho-Schellenberg, and E. Patton. 2011. Co-management and the co-production of knowledge: learning to adapt in Canada's arctic. Global environmental Change 21(3):995-1004. https://doi.org/10.1016/j. gloenvcha.2011.04.006

Battiste, M. 1998. Enabling the autumn seed: towards a decolonized approach to Aboriginal knowledge, language, and education. Canadian Journal of Native Education 22(1):16-27.

Beckerman, S., P.I Erickson, J. Yost, J. Regalado, L. Jaramillo, C. Sparks, M. Iromenga, and K. Long. 2009. Life histories, blood revenge, and reproductive success among the Waorani of Ecuador. Proceedings of the National Academy of Sciences 106 (20):8134-8139. https://doi.org/10.1073/pnas.0901431106 
Beech, N., R. MacIntosh, and D. MacLean. 2010. Dialogues between academics and practitioners: the role of generative dialogic encounters. Organization Studies 31(9-10):1341-1367. https://doi.org/10.1177/0170840610374396

Bell, D. M., and K. Pahl. 2018. Co-production: towards a utopian approach. International Journal of Social Research Methodology 21(1):105-117. https://doi.org/10.1080/13645579.2017.1348581

Bernstein, J. H. 2015. Transdisciplinarity: a review of its origins, development, and current issues. Journal of Research Practice 11 (1):R1.

Bieluch, K. H., K. P. Bell, M. F. Teisl, L. A. Lindenfeld, J. Leahy, and L. Silka. 2016. Transdisciplinary research partnerships in sustainability science: an examination of stakeholder participation preferences. Sustainability Science 12/1:87-104. https://doi.org/10.1007/s11625-016-0360-x

Bohensky, E. L., and Y. Maru. 2011. Indigenous knowledge, science, and resilience: What have we learned from a decade of international literature on "integration"? Ecology and Society 16 (4):6. https://doi.org/10.5751/ES-04342-160406

Brandt, P., A. Ernst, F. Gralla, C. Luederitz, D.J. Lang, J. Newig, F. Reinert, D. J. Absone, and H. Von Wehrden. 2013. A review of transdisciplinary research in sustainability science. Ecological Economics 92:1-15. https://doi.org/10.1016/j.ecolecon.2013.04.008

Brayboy, B. M., and D. Deyhle. 2000. Insider-outsider: researchers in American Indian communities. Theory Into Practice 39(3):163-169. https://doi.org/10.1207/s15430421tip3903_ 7

Buzinde, C. N., D. Manuel-Navarrete, and T. Swanson. 2020. Coproducing sustainable solutions in indigenous communities through scientific tourism. Journal of Sustainable Tourism 28 (9):1255-1271. https://doi.org/10.1080/09669582.2020.1732993

Chilisa, B. 2017. Decolonising transdisciplinary research approaches: an African perspective for enhancing knowledge integration in sustainability science. Sustainability Science 12 (5):813-827. https://doi.org/10.1007/s11625-017-0461-1

Cole, A. 2017. Towards an Indigenous transdisciplinarity. Transdisciplinary Journal of Engineering \& Science 8:127-150. https://doi.org/10.22545/2017/00091

Cram, F., and H. Phillips. 2012. Claiming interstitial space for multicultural, transdisciplinary research through community-up values. International Journal of Critical Indigenous Studies 5 (2):36-49. https://doi.org/10.5204/ijcis.v5i2.89

Darbellay, F., M. Cockell, J. Billotte and F. Waldvogel, editors. 2008. A Vision of Transdisciplinarity: Laying Foundations for a World Knowledge Dialogue. CRC Press. https://doi. org/10.1201/9781439808023

Dei, G. 2000. Rethinking the role of Indigenous knowledges in the academy. The International Journal of Inclusive Education 4 (2):134-147. https://doi.org/10.1080/136031100284849

Díaz, S., S. Demissew, J. Carabias, C. Joly, M. Lonsdale, N. Ash, A. Larigauderie, J. R. Adhikari, S. Arico, A. Baldi, et al. 2015. The IPBES Conceptual Framework-connecting nature and people. Current Opinion in Environmental Sustainability 14:1-16. https://doi.org/10.1016/j.cosust.2014.11.002
Frandy, T. 2018. Indigenizing sustainabilities, sustaining indigeneities: decolonization, sustainability, and education. Journal of Sustainability Education 18.

Freire, P. 1970. Pedagogy of the oppressed. The Continuum Publishing Corporation, York City, NY.

Fritz, L., and F. Meinherz. 2020. Tracing power in transdisciplinary sustainability research: an exploration. GaiaEcological Perspectives for Science and Society 29: 41-51. https:// doi.org/10.14512/gaia.29.1.9

Grilli, G., and S. Notaro. 2019. Exploring the influence of an extended theory of planned behaviour on preferences and willingness to pay for participatory natural resources management. Journal of Environmental Management 232:902-909. https://doi.org/10.1016/j.jenvman.2018.11.103

Grosfoguel, R. 2011. Decolonizing post-colonial studies and paradigms of political-economy: transmodernity, decolonial thinking, and global coloniality. Transmodernity: Journal of Peripheral Cultural Production of the Luso-Hispanic World 1(1).

Hargreaves, T. 2011. Practice-ing behaviour change: applying social practice theory to pro-environmental behaviour change. Journal of Consumer Culture 11(1):79-99. https://doi. org/10.1177/1469540510390500

Hill, R., Ç. Adem, W.V. Alangui, Z. Molnár, Y. AumeeruddyThomas, P. Bridgewater, M. Tengo, R. Thaman, C. Y. Adou Yao, F. Berkes, et al. 2020. Working with indigenous, local and scientific knowledge in assessments of nature and nature's linkages with people. Current Opinion in Environmental Sustainability 43:8-20. https://doi.org/10.1016/j.cosust.2019.12.006

Hodge, F. S. 2012. No meaningful apology for American Indian unethical research abuses. Ethics \& Behavior 22(6):431-444. https://doi.org/10.1080/10508422.2012.730788

Johnson, J. T., R. Howitt, G. Cajete, F. Berkes, R.P. Louis, and A. Kliskey. 2016. Weaving Indigenous and sustainability sciences to diversify our methods. Sustainability Science 11(1):1-11. https://doi.org/10.1007/s11625-015-0349-X

Klenk, N., and K. Meehan. 2015. Climate change and transdisciplinary science: problematizing the integration imperative. Environmental Science \& Policy 54:160-167. https:// doi.org/10.1016/i.envsci.2015.05.017

Kofinas, G., 2002. Community contributions to ecological monitoring: knowledge coproduction in the US-Canada arctic borderlands. In: The Earth Is Faster Now: Indigenous Observations of Arctic Environmental Change. Arctic Research Consortium of the United States. Fairbanks. 54-91.

Koskinen, I., and U. Mäki. 2016. Extra-academic transdisciplinarity and scientific pluralism: what might they learn from one another? European Journal for Philosophy of Science 6(3):419-444. https:// doi.org/10.1007/s13194-016-0141-5

Kvale, S. 1996. InterViews: an introduction to qualitive research interviewing. Sage.

Lam, D., E. Hinz, D. Lang, M. Tengö, H. von Wehrden, and B. Martín-López. 2020. Indigenous and local knowledge in sustainability transformations research: a literature review. Ecology and Society 25(1):3. https://doi.org/10.5751/ES-11305-250103 
Latour, B. 2016. A dialog about a new meaning of symmetric anthropology. Interview by Carolina Miranda. In P. Charbonnier, G. Salmon, \& P. Skafish, editors Comparative Metaphysics: Ontology After Anthropology. 327-345.

Latulippe, N., and N. Klenk. 2020. Making room and moving over: knowledge co-production, Indigenous knowledge sovereignty and the politics of global environmental change decision-making. Current Opinion in Environmental Sustainability 42:7-14. https://doi.org/10.1016/j.cosust.2019.10.010

Long, K. 2019. God in the Rainforest: Missionaries and the Waorani in Amazonian Ecuador. Oxford University Press. https:// doi.org/10.1093/oso/9780190608989.001.0001

Lotz-Sisitka, H. B., 2017. Decolonisation as future frame for environmental and sustainability education: embracing the commons with absence and emergence. In P. Corcoran and $\mathbf{J}$. Weakland, editors. Envisioning Futures for Environment and Sustainability Education. Wageningen Academic Publishers., Wageningen. 45-62. https://doi.org/10.3920/978-90-8686-846-9_2

Mamdani, M. 2019. Decolonising universities. In T. Halvorsen, K. Skare Orgeret, and R. Krovel, editors. Sharing Knowledge, Transforming Societies: The Norhed Programme 2013-2020. African Books Collective, 48-67. https://doi.org/10.18772/22019083351.6

Manuel-Navarrete, D. 2015. Double coupling: modeling subjectivity and asymmetric organization in social-ecological systems. Ecology and Society 20(3):26. https://doi.org/10.5751/ ES-07720-200326

Manuel-Navarrete, D., C. Morehart, B. Tellman, H. Eakin, J.M. Siqueiros-García, and B.H. Aguilar. 2019. Intentional Disruption of Path-dependencies in the Anthropocene: Gray versus Green Water Infrastructure Regimes in Mexico City, Mexico. Anthropocene 26(100209). https://doi.org/10.1016/j.ancene.2019.100209

McGregor, S. 2015. The Nicolescuian and Zurich approaches to transdisciplinarity. Integral Leadership Review April - June.

Mignolo, W. D. 2017. Coloniality is far from over, and so must be decoloniality. Afterall: A Journal of Art, Context and Enquiry 43(1):38-45. https://doi.org/10.1086/692552

Miller, C.A., and C. Wyborn. 2020. Co-production in global sustainability: histories and theories. Environmental Science \& Policy 113:88-95. https://doi.org/10.1016/j.envsci.2018.01.016

Mistry, J., and A. Berardi. 2016. Bridging indigenous and scientific knowledge. Science 352(6291):1274-1275. https://doi. org/10.1126/science.aaf1160

Nakata, M. 2002. Indigenous knowledge and the cultural interface: underlying issues at the intersection of knowledge and information systems. IFLA journal 28(5-6):281-291. https://doi. org/10.1177/034003520202800513

Newig, J., S. Jahn, D.J. Lang, J. Kahle, and M. Bergmann. 2019. Linking modes of research to their scientific and societal outcomes. Evidence from 81 sustainability-oriented research projects. Environmental Science \& Policy 101:147-155. https://doi. org/10.1016/j.envsci.2019.08.008

Nicolescu, B. 2010. Methodology of transdisciplinarity-levels of reality, logic of the included middle and complexity.
Transdisciplinary Journal of Engineering \& Science, 1:17-32 https://doi.org/10.22545/2010/0009

Nicolescu, B. 2014. From Modernity to Cosmodernity: Science, Culture, and Spirituality. SUNY Press.

Nowotny, H., P. Scott, and M. Gibbons. 2003. Introduction: 'Mode 2' revisited: the new production of knowledge. Minerva 41 (3):179-194.

Parrado-Rosselli, A. 2007. A collaborative research process studying fruit availability and seed dispersal within an indigenous community in the Middle Caqueta River region, Colombian Amazon. Ecology and Society 12(2):39. https://doi.org/10.5751/ ES-02219-120239

Raffles, H. 2002. Intimate knowledge. International Social Science Journal 54(3):325-335. https://doi.org/10.1111/1468-2451.00385

Rival, L. 1993. The growth of family trees: understanding Huaorani perceptions of the forest. Man 28(4): 635-652. https:// doi.org/10.2307/2803990

Rosendahl, J., M.A. Zanella, S. Rist, and J. Weigelt. 2015. Scientists' situated knowledge: strong objectivity in transdisciplinarity. Futures 65:17-27. https://doi.org/10.1016/j.futures.2014.10.011

Santos Boaventura de Sousa. 2014. Epistemologies of the South: Justice against Epistemicide. Paradigm Publishers, Boulder, CO.

Schmidt, L., and M. Neuburger. 2017. Trapped between privileges and precariousness: tracing transdisciplinary research in a postcolonial setting. Futures 93:54-67. https://doi.org/10.1016/j. futures.2017.07.005

Simpson, L. 2001. Aboriginal peoples and knowledge: decolonizing our processes. The Canadian Journal of Native Studies 21(1):137-148.

Talbot, S. 2002. Academic Indianismo: social scientific research in American Indian studies. American Indian Culture and Research Journal 26(4):67-96. https://doi.org/10.17953/aicr.26.4.j3w2317170370937

Tuhiwai-Smith, L. 1999. Decolonizing methodologies: research and indigenous peoples. University of Otago Press. Dunedin, New Zealand.

Turnhout, E., T. Metze, C. Wyborn, N. Klenk, and E. Louder. 2020. The politics of co-production: participation, power, and transformation. Current Opinion in Environmental Sustainability 42:15-21. https://doi.org/10.1016/j.cosust.2019.11.009

Velasquez Runk, J. 2014. Enriching indigenous knowledge scholarship via collaborative methodologies: beyond the high tide's few hours. Ecology and Society 19(4):37. https://doi. org/10.5751/ES-06773-190437

wa Thiong'o, N. 1986. Decolonising the Mind. James Currey Ltd., London

Weston, C., T. Gandell, J. Beauchamp, L. McAlpine, C. Wiseman, and C. Beauchamp. 2001. Analyzing interview data: The development and evolution of a coding system. Qualitative Sociology 24(3):381-400. https://doi.org/10.1023/a:1010690908200

Zingerli, C. 2010. A sociology of international research partnerships for sustainable development. The European Journal of Development Research 22(2):217-233. https://doi.org/10.1057/ ejdr.2010.1 